\title{
Stereological Studies on Several Ducts and Vessels by Injection Method of Acrylic Resin
}

\author{
XXVII. Arteral distribution of the masseter \\ muscle in some mammals
}

By

\author{
Issei Fujiwara \\ Department of Anatomy, Osaka Dental University, Osaka \\ (Director: Prof. Y. Taniguchi) \\ (With 26 Figures in 4 Plates, One Table)
}

By means of the acryl plastic injection, the arterial distribution of the temporal muscle in some mammals was surveyed comparatively by $\mathrm{Fu} \mathrm{jimoto} \mathrm{(1959),} \mathrm{and} \mathrm{then} \mathrm{that} \mathrm{of} \mathrm{the} \mathrm{medial} \mathrm{pterygoid} \mathrm{muscle}$ by Tsuji (1969).

The present author will deal with a three-dimensional observation on the arterial supply of the masseter muscle in dog, rabbit, goat and human fetus, employing the plastic injection corrosion method. Recently, Y o s hik a w a et al. (1961) have made a comparative study of the masseter muscle, and reported the formation of a detailed laminar arrangement of it. Accordingly, the present author has surveyed on the arterial distribution of the muscle, being as careful as possible on the laminar arrangement by them.

\section{Materials and Method}

Animals used: 18 dogs, 18 rabbits, 12 goats and 17 human fetuses (6-10 months).

Acryl plastic injection was applied by method of $\mathrm{T}$ a n i g u c hi, $\mathrm{O}$ h t $\mathrm{a}$ and $\mathrm{T} \mathrm{a} \mathrm{jir} \mathrm{i} \mathrm{(1952} \mathrm{and} \mathrm{1955).} \mathrm{The} \mathrm{plastic} \mathrm{material} \mathrm{was} \mathrm{injected}$ through cannulae inserted into the common carotid arteries. Most of the injected heads were digested with alkali to corrosion casts. Some of them were preserved in the formalin solution for dissecting technique. These specimens were submitted to the dissection and observation under the binocular magnifier. 


\section{Observations}

Dog :

Masseteric branches arise from the following arteries in $18 \mathrm{ex}-$ amples observed: 1. Facial artery, 2. Superficial temporal artery, 3. Transverse facial artery, 4. Masseteric artery, 5. Buccal artery.

1. Facial artery

One to five masseteric branches $(0.3-0.6$, M. $0.48 \mathrm{~mm})$ leave the artery (figs. 1, 2, 4, 7).

The proximalmost branch (fig. 7) arises from the posterior wall of the facial artery, 5-7 $\mathrm{mm}$ distal to the beginning of the submental artery, between it and the mandibular basis. The branch passes lateralward or posterolaterally along the overlap of the masseter on the medial pterygoid muscle from the inferior margin of the insertion of the masseter. After sending off the R. gl. submandibularis backward, it spreads upward and forward within the superficial masseter from the antero-inferior end of it, for supplying the anterior half of the insertion of it.

The middle branch (figs. 1,4) arises from the superior wall of the facial artery when it starts out of the mandibular basis and is located along the anterior margin of the masseter. The branch immediately enters the superficial masseter from its anterior edge and spreads upward and backward to supply all layers of it fan-shapedly.

The distalmost branches (figs. 1, 2, 4), fine two or three, arise from the superior wall of the facial artery in the middle of the anterior margin of the masseter. They are distributed to the small area near the anterior margin and the fatty tissue in front of it.

2. Superficial temporal artery

The masseteric branch $(0.3-0.4$, M. $0.32 \mathrm{~mm}$, fig. 3) arises from the lateral or anterior wall of the artery, 1-2 mm distal to the beginning of it in 5 cases. The branch passes forward for 3-5 mm along inferior to the transverse facial artery, and is distributed to the secondary layer of the superficial masseter from the postero-inferior end of it.

\section{Transverse facial artery}

As the main stream, the artery turns to masseteric branches. (0.6-0.9, M. $0.78 \mathrm{~mm}$, figs. 1, 3), but fine twigs of it come up to the masseteric fascia and skin. The artery is immediately located under the fascia, and supplies many twigs to the venter of the superficial masseter, passing forward horizontally. 


\section{Masseteric artery}

The artery (0.9-1.1, M. $1.02 \mathrm{~mm}$, figs. 1, 4, 5, 6) leaves the lateral wall of the posterior deep temporal artery and usually branches into four twigs $(0.2-0.8$, M. $0.58 \mathrm{~mm})$ immediately after coming out of the mandibular notch. They spread supero-anteriorly to inferiorly (figs. $5,6)$. Among them, twigs to the superior and anterior invade into between the zygomatic arch and the muscular process, and are distributed to the zygomaticomandibular and maxillomandibular muscles. One of them ascends to supply the intermediate masseter, and the other fine twigs sometimes run posterosuperiorly to supply the zygomaticomandibular muscle (fig. 6).

5. Buccal artery

Masseteric branch $(0.15-0.35$, M. $0.24 \mathrm{~mm}$, fig. 8) of the artery arises from the lateral or posterior wall of it, when the artery appears on the face passing around the anterior margin of the temporal muscle. The branch divides into two which run backward along the medial surface of the zygomatic arch. They are distributed to the origins of the superficial and deep masseter, and the maxillomandibular muscle.

\section{Rabbit :}

Masseteric branches arise from the following arteries in 18 examples observed: 1. Facial artery, 2. Mandibular angle branch of the superficial temporal artery, 3. Transverse facial artery, 4. Buccal artery.

1. Facial artery

Masseteric branches $(0.3-0.6$, M. $0.47 \mathrm{~mm})$ arise from the following parts :

1) About $7 \mathrm{~mm}$ proximal to the vascular notch of the mandibular bassis, where the facial passes through; the masseteric branches (figs. 11,13 ), one to three in number, arise from the opposite (lateral or posterior) wall of the origin of the submental artery. They pass around the inferior surface of the venter of the maxillomandibular muscle onto the lateral side of the muscle, and are distributed to the anterior half of the superficial masseter upward or superoposteriorly. One of these branches runs backward along the maxillomandibular muscle (fig. 13). 2) At the vascular notch; the masseteric branch (figs. 9-13) ascends along the anterior margin of the superficial masseter or the maxillomandibular muscle and supplies the anterior one-third of the superficial masseter. 3) Proximal or distal to the beginnings of the inferior and superior labial arteries; the masseteric 
fine branches (figs. 9, 10, 12), giving off small buccal twigs, leave the artery and are distributed to the anterior margin of the secondary layer of the superficial masseter and the origin of the maxillomandibular muscle.

2. Mandibular angle branch of the superficial temporal artery

The branch $(0.5-0.6$, M. $0.54 \mathrm{~mm}$, fig. 15) arises downward from the anterior wall of the artery about $2 \mathrm{~mm}$ distal to its beginning. It runs up to the inferoposterior end of the masseter along its posterior margin, and enters it, spreading into fine masseteric twigs forward or infero-anteriorly. They are distributed to the insertion of the masseter.

\section{Transverse facial artery}

The artery $(0.8-0.9$, M. $0.82 \mathrm{~mm}$, figs. $9,10,12,15)$ separates from the superficial temporal about $8 \mathrm{~mm}$ distal to the beginning of the posterior auricular. It, being almost as thick as or thicker than the parent artery, runs forward under the fascia of the masseter up to the anterior margin of it. On the corrosion specimens, it is possible to separate the arterial network of the intermediate muscle clearly from that of the superficial masseter, which is supplied with rich twigs of the main stream (figs. 10, 12). The artery gives. off the supero-anterior and superior (or superoposterior) twigs (figs. 9, 10, 12). The former arches into deep downward and forward, for supplying the intermediate masseter and the zygomaticomandibular muscles (fig. 10). In 3 cases, the latter is distributed to the deep masseter (fig. 12).

4. Buccal artery

The masseteric branch (0.4-0.7, M. $0.52 \mathrm{~mm}$, fig. 14) from the lateral wall, after the artery gives off a temporal muscular branch, runs lateralward and is distributed to the origins of the intermediate and deep masseter.

\section{Goat :}

Masseteric branches arise from the following arteries in $12 \mathrm{ex}-$ amples observed: 1. Mandibular angle branch of the external carotid artery, 2. Superficial temporal artery, 3. Transverse facial artery, 4. Deep temporal artery, 5. Buccal artery.

1. Mandibular angle branch of the external carotid artery

The branch $(1.2-1.6$, M. $1.39 \mathrm{~mm})$ arises from the anterior wall of the external carotid artery in 8 cases (fig. 16), immediately distal to the beginning of the lingual artery, or from the inferior wall of 
the transverse facial artery in 4 cases (vide infra, fig. 19). It passes downward along the anterolateral side of the external carotid artery to the mandibular tuber, and then forward along the mandibular basis. It gives rich twigs to the parotid and submandibular glands and the submandibular lymph nodes. The main stream of the angle branch divides into two, which run forward and upward from the mandibular tuber and are distributed to the insertion and part of the venter of the superficial masseter, anastomosing (c. $0.15 \mathrm{~mm}$ ) with peripheries of the transverse facial artery.

\section{Superficial temporal artery}

The masseteric branch $(1.2-1.4$, M. $1.32 \mathrm{~mm}$, figs. 16, 17) of the artery arises from the anterior wall of it immediately after the beginning of the transverse facial artery. The branch divides into two, the anterior and supero-anterior. They pass forward 5-10 $\mathrm{mm}$ superior to the transverse facial artery and supply the deep masseter.

\section{Transverse facial artery}

The artery (1.9-2.2, M. $2.03 \mathrm{~mm}$, figs. 16, 17) arises from the anterior wall of the external carotid artery in contact with the beginning of the superficial temporal artery, or from the superficial temporal about $5 \mathrm{~mm}$ distal to the beginning of it in 4 cases (fig. 19). It runs forward or anterolaterally at the posterior margin of the masseter and continues horizontally up to the anterior margin of it along the middle height of its venter. En route 5 to 10 masseteric branches $(0.5-0.7$, M. $0.64 \mathrm{~mm}$, figs. 16, 17, 19) leave the superior, inferior and medial walls, upward and downward, respectively.

In case the proximalmost branch of them is well developed, it leaves the transverse facial as the mandibular angle branch (fig. 19). It supplies the venter and insertion of the superficial masseter from its postero-inferior end. The other many branches supply rich twigs to the whole superficial and intermediate masseter. The distalmost branch in the anterior margin of the masseter runs downward to supply the maxillomandibular muscle. The upward branches of them are especially distributed to the origin of the maxillomandibular muscle which originates from the malar prominence.

\section{Deep temporal artery}

The artery $(0.8-0.9, M .0 .89 \mathrm{~mm})$ arises from the lateral wall of the external carotid artery, 3-5 $\mathrm{mm}$ distal to the beginning of the posterior rete branch in contact with the mandibular collum of the condylar process. The main stream of it ascends into the temporal 
muscle, and the masseteric branch (0.4-0.6, M. $0.50 \mathrm{~mm}$, fig. 18) leaves the lateral wall of the artery lateralward in the height of the mandibular caput. The branch supplies small twigs to the origin of the zygomaticomandibular muscle and the temporomandibular joint.

\section{Buccal artery}

The masseteric branches $(0.5-0.8$, M. $0.67 \mathrm{~mm}$, figs. 20,21$)$, two to seven in number, leave the anterior and posterior walls of the buccal artery, which passes lateralward between the zygomatic arch and the insertion of the temporal muscle. Two to five of them run superoposteriorly, and one or two downward. The former is distributed to the origin of the maxillomandibular muscle and the venter of the zygomaticomandibular muscle, and the latter chiefly supplies the cheek, but the anterior margin of the origin of the maxillomandibular muscle is supplied by twigs of them.

\section{Human fetus:}

Masseteric branches arise from the following arteries in 17 examples observed: 1. Facial artery, 2. External carotid artery, 3. Transverse facial artery, 4. Masseteric artery, 5. Posterior deep temporal artery, 6. Anterior deep temporal artery.

\section{Facial artery}

The masseteric branches $(0.2-0.5$, M. $0.37 \mathrm{~mm}$, figs. $22,23,25)$ arise before the facial artery appears to the mandibular basis (fig. 23), and between the beginnings of the superior and inferior labial arteries, respectively. The former is observed two in number. The proximal one of them arises from the lateral wall of the facial artery 2-4 $\mathrm{mm}$ distal to the beginning of the submental artery, and the distal one leaves the artery immediately after it bends lateralward for appearing to the mandibular basis. They come up to the anteroinferior end of the superficial masseter, while the proximal one passes upward in the muscle. The latter ascends along the anterior margin of the superficial masseter. Both muscular branches are distributed to the insertions of the superficial and intermediate masseter.

\section{External carotid artery}

The masseteric branches $(0.2-0.5$, M. $0.39 \mathrm{~mm}$, figs. $22,23,25)$ are observed two or three in number.

The one arises from the anterior wall of the external carotid artery about $3 \mathrm{~mm}$ distal to the beginning of the posterior auricular artery. It runs anteriorly toward the mandibular angle, giving off a twig to the medial pterygoid muscle ( $\mathrm{Tsuji}$ 1969) and the 
submandibular lymph nodes, and reaches the inferoposterior end of the masseter. It passes anterosuperiorly in the muscle. The other also leaves the anterior wall of the external carotid in contact with or pretty proximal to the beginning of the superficial temporal. It passes forward between the former and the transverse facial artery after giving off several parotid twigs ( $\mathrm{K}$ i t a $\mathrm{m} \mathrm{u}$ r a 1970), and reaches the inferior one-third of the posterior margin of the masseter.

Both are distributed to the whole superficial and intermediate masseter. Peripheries of them anastomose (c. $0.10 \mathrm{~mm}$ ) with the masseteric branches of the facial artery right under the masseteric fascia.

3. Transverse facial artery

The artery arises, freely or in common with the zygomaticoorbital and the masseteric branch, from the anterior or anterolateral wall of the superficial temporal artery or of the external carotid (figs. 22, 25). It enters the masseter from the meeting place of the superficial and deep masseter, that is, the superior one-third of the posterior margin of the masseter. Prior to this entrance, a twig is given off from the artery to supply the skin on the masseter, and the artery usually divides (figs. 25,26$)$ into the superficial $(0.4-0.6$, M. $0.53 \mathrm{~mm}$ ) and deep (0.6-0.8, M. $0.71 \mathrm{~mm})$ muscular branches. The superficial branch runs forward right under the masseteric fascia between the zygomaticoorbital artery and the masseteric branch of the external carotid. It gives many twigs upward and downward, respectively, which supply the whole superficial, intermediate masseter and the insertion of the deep masseter until the branch reaches the anterior margin of the muscles. The deep branch enters forward between the intermediate and deep masseter and supplies both, but it disappears at the anterior margin of the deep masseter.

\section{Masseteric artery}

The artery $(0.5-0.6$, M. $0.51 \mathrm{~mm}$, figs. $22,25,26)$ arises from the superior or superolateral wall of the maxillary artery in contact with the beginning of the posterior deep temporal artery in 11 cases or about $1.5 \mathrm{~mm}$ proximal to the beginning of the artery in 6 cases. The masseteric artery runs lateralward through the mandibular notch, and then infero-anteriorly. It passes between the deep masseter and the maxillomandibular muscles and supplies many twigs to them.

5. Posterior deep temporal artery

The main stream of the artery is distributed to the temporal muscle, but small twigs (c. $0.3 \mathrm{~mm}$, figs. 24,26 ) of it near its begin- 
ning are supplied to the maxillomandibular muscle.

6. Anterior deep temporal artery

The massetric branch $(0.4-0.5$, M. $0.47 \mathrm{~mm}$, figs. 24,26$)$ of the artery arises from the lateral or anterolateral wall of it in the height of the top of the muscular process. The main stream of the branch appears to the skin in front of and on the masseter through the anterior margin of the process. En route small twigs are derived from the branch in the medial side of the muscular process and are distributed to the maxillomandibular and zygomaticomandibular muscles.

\begin{tabular}{|c|c|c|c|c|}
\hline M. masseter & Dog & Rabbit & Goat & Human fetus \\
\hline & $\begin{array}{l}\text { Facial } \\
\text { Transverse } \\
\text { facial }\end{array}$ & $\begin{array}{l}\text { Facial } \\
\text { Transverse } \\
\text { facial }\end{array}$ & $\begin{array}{l}\text { Transverse } \\
\text { facial }\end{array}$ & $\begin{array}{l}\text { Transverse facial } \\
\text { External carotid }\end{array}$ \\
\hline superficialis & $\begin{array}{l}\text { Superficial } \\
\text { temporal } \\
\text { Buccal } \\
\text { Masseteric }\end{array}$ & $\begin{array}{l}\text { Mandibular } \\
\text { angle branch* }\end{array}$ & $\begin{array}{l}\text { Mandibular } \\
\text { angle branch** }\end{array}$ & Facial \\
\hline intermedius & Masseteric & $\begin{array}{l}\text { Transverse } \\
\text { facial } \\
\text { Buccal } \\
\text { Mandibular } \\
\text { angle branch* }\end{array}$ & $\begin{array}{l}\text { Transverse } \\
\text { facial }\end{array}$ & $\begin{array}{l}\text { Transverse facial } \\
\text { External carotid }\end{array}$ \\
\hline profundus & Buccal & $\begin{array}{l}\text { Transverse } \\
\text { facial } \\
\text { Buccal } \\
\text { Mandibular } \\
\text { angle branch* }\end{array}$ & $\begin{array}{l}\text { Superficial } \\
\text { temporal }\end{array}$ & $\begin{array}{l}\text { Transverse facial } \\
\text { Masseteric }\end{array}$ \\
\hline $\begin{array}{l}\text { zygomatico- } \\
\text { mandibularis }\end{array}$ & Masseteric & $\begin{array}{l}\text { Transverse } \\
\text { facial }\end{array}$ & $\begin{array}{l}\text { Buccal } \\
\text { Deep temporal }\end{array}$ & $\begin{array}{l}\text { Masseteric } \\
\text { Anterior deep } \\
\text { temporal }\end{array}$ \\
\hline \multirow{2}{*}{$\begin{array}{l}\text { maxillo- } \\
\text { mandibularis }\end{array}$} & Masseteric & Buccal & $\begin{array}{l}\text { Transverse } \\
\text { facial }\end{array}$ & $\begin{array}{l}\text { Masseteric } \\
\text { Anterior deep } \\
\text { temporal }\end{array}$ \\
\hline & Buccal & Facial & Buccal & $\begin{array}{l}\text { Posterior deep } \\
\text { temporal }\end{array}$ \\
\hline
\end{tabular}

* out of superficial temporal, ** out of external carotid artery

\section{Discussion}

Citing the laminar arrangement mentioned by $\mathrm{Y}$ os hikaw a (1961), the present author made an attempt to fix the relations between the subdivided muscles of the masseter and the arterial 
distribution into a Table. However, the detailed area of each layer did not accurately correspond to the respective arterial network which might come from a special arterial resource. This difference in results will be made from the researching approach, that is, the present author has made observations on the corrosion specimens of the arterial structure chiefly. He has believed that the new and detailed findings on the arterial distribution of the masseter were able to make through the excellent paper worked by Yoshikawa et al.

\section{Facial artery}

Tsusaki (1954) described that the facial artery supplied the masticating muscles, the submandibular gland, the lips and the face in rabbit. $\mathrm{Kamijo}$ (1967) stated the masseteric branch of the facial artery in man supplied from the anterior region of the masseter. In the present paper, the masseteric branches of the artery generally supplied the insertion of the masseter in dog and rabbit. And, one of the branches entered the special muscle bundle which ran backward along the mandibular basis in rabbit. The branch in human fetus was weaker than in dog.

\section{Transverse facial and superficial temporal arteries}

Elle n berger et al. (1891) stated that the Rr. masseterici of the superficial temporal artery in dog supplied the masseter and skin, and a fine branch, the transverse facial artery of the superficial temporal gave twigs to the buccinator muscle and skin.

Miller et al. (1964) in dog stated that the masseteric artery of the superficial temporal artery was a relatively large branch, usually over $1 \mathrm{~mm}$ in diameter, which arose from the anterior side of the superficial temporal near its origin or from the maxillary artery directly. It ran forward and entered the deep surface of the masseteric muscle where it passed anteroventrally between the muscle and the masseteric fossa. Usually several other fine branches arose from the vessel and supplied other structures. In above half of the specimens they came off separately from the superficial temporal close to the masseteric artery, still other branches supplied the skin and occasionally the temporomandibular joint capsule. The temporal branches, variable in number, size, and origin, arose from the distal half of the superficial temporal artery. They supplied the temporal muscle, and some of them ran medial to the zygomatic arch and then ventral to it to supply the masseter.

The present observations were that the masseteric branches to the superficial masseter, which arose from the facial and the trans- 
verse facial, respectively, were seen as the main distributing resource in $\mathrm{dog}$, and the strong transverse facial artery in rabbit. The distributing area of this artery was extended beyond the superficial masseter to the intermediate, the deep and the zygomaticomandibular muscles. The masseteric artery of the maxillary, however, was not present in rabbit, so the well-developed transverse facial would compensate the masseteric artery. While, the distributing area of the transverse facial, the deep temporal and the buccal arteries was also wide in goat, because of the lacking of the facial. In human fetus, both the transverse facial and the facial were the main supply to the superficial, intermediate and deep masseter, but most stream of the transverse facial came up on the masseteric fascia and skin. The present author did not constantly observe such a large masseteric artery of the superficial temporal as $\mathrm{Miller}$ et al. mentioned.

This artery and the temporal branch by him were regarded as all inclusive of the transverse facial, the masseteric branch of it, and the mandibular angle branch of it or the superficial temporal artery, considering from their origins.

\section{Masseteric and deep temporal arteries}

Elle $\mathrm{nberger}$ et al. in dog stated that the R. massetericus of the posterior deep temporal artery bent at the Incisura semilunaris and entered the masseter deeply. Mille $\mathrm{r}$ et al. described also in dog that one branch of the posterior deep temporal passed through the mandibular notch to the masseter muscle. This was the R. massetericus, and anastomosed with the masseteric artery, the main supply to the masseter, as it ran on its deep surface.

The masseteric artery was small in dog in this paper as they mentioned. The artery in rabbit was not observed. In goat, the main stream of the deep temporal supplied the temporal muscle, and a small part of it supplied the maxillomandibular muscle only as the masseteric artery in company with the masseteric branch of the buccal artery. In human fetus, the masseteric artery and the branch of the posterior deep temporal were the main stream to deep parts of the masseter; the anterior deep temporal supplied the maxillomandibular and zygomaticomandibular muscles. This vessel was rather thick and had a wide supplying territory in the masseter. It was interesting that these features resembled those of the massetericus of the buccal artery in animals observed.

4. Mandibular angle branch

This branch named by the present author was seen in rabbit and goat, especially stronger in the former. It seemed to be a twig 
of the superficial temporal in rabbit, but of the external carotid (or of the transverse facial) in goat. Its feature was peculiar to these species, in which the posterior part of the insertion of the masseter has shown a good development.

\section{Buccal artery}

Miller et al. stated that larger twigs of the buccinator artery in dog were distributed to the masseter, temporal, and buccinator muscles. H a t a (1967) described that the terminal branch of the buccal artery in dog entered the maxillomandibular muscle and supplied it, and the artery in rabbit en route gave a twig of the $R$. buccalis to the maxillomandibular muscle while the $R$. massetericus, forming various relationships with the arising of the $R$. m. temporalis, ran upward slightly laterally up to medial to the zygomatic arch, where it trifurcated, the anterior, the middle and the posterior. The anterior and posterior branches supplied the origin of the masseter. Also, the branch to the Mm. intermedius et profundus of the buccal artery was described by $\mathrm{H}$ at a. Then, he stated that many twigs, termini of the buccal artery supplied the superficial and maxillomandibular muscles in goat, but none of the artery supplied the muscle in human fetus.

In the present paper, the masseteric branches, termini of the buccal in general were distributed to the upper half of the anterior part of the masseter except in human fetus. The fact that many twigs of the buccal artery in rabbit were supplied to not only the deep layers of the masseter, but also the Pars orbitalis $(\mathrm{H}$ a $\mathrm{n}$ a $\mathrm{i}$ et al., 1960) of the temporal muscle, might tell of the close relations between these two muscles.

\section{Conclusions}

1. The observations were made on the arterial distributing branches of the masseter muscle in dog, rabbit, goat and human fetus by means of the acryl plastic corrosion method.

2. The masseteric muscular branches, as shown in the Table, were given off from the following arteries:-

To the M. masseter superficialis : the facial and transverse facial in goat; the transverse facial and external carotid in human fetus, and locally the superficial temporal, buccal and masseteric (dog), the mandibular angle branch (rabbit and goat) and the facial (human fetus).

To the M. masseter intermedius: the masseteric in dog; the transverse facial and buccal (locally the mandibular angle branch) 
in rabbit; the transverse facial in goat; the transverse facial and external carotid in human fetus.

To the M. masseter profundus : the buccal in dog; the transverse facial (locally the mandibular angle branch) in rabbit; the superficial temporal in goat; the transverse facial and masseteric in human fetus.

To the M. zygomaticomandibularis: the masseteric in dog; the transverse facial in rabbit; the buccal (locally the deep temporal) in goat; the masseteric and anterior deep temporal in human fetus.

To the M. maxillomandibularis : the masseteric (locally the buccal) in dog; the buccal (locally the facial) in rabbit; the transverse facial (locally the buccal) in goat; the masseteric and anterior deep temporal (locally the posterior deep temporal) in human fetus.

The author should like to express his thanks to Professor Y. T a n ig u chi for guidance and encouragement shown to him, and also to Assistant Professor $\mathrm{Y}$. O h $\mathrm{t}$ a for his help in surveying specimens and preparing the manuscript.

\section{Literature cited}

1) Ellenberger, W. und H. Ba um, 1891: Systematische und topographische Anatomie des Hundes. Berlin, 268-386.

2) Fujimoto, T., 1959: Cubical anatomy of several ducts and vessels by injection method of acrylic resin. V. Arterial distribution of the temporal muscle in some mammals. Okajimas Fol. anat. jap., 33, 389-424.

3) Hanai, H., Y. Ohtan i, H. Sawa and I. Fujiwara, 1960: On relations between $M$. temporalis and the superior head of $M$. pterygoideus lateralis in rabbit. Okajimas Fol. anat: jap., 34, 299-321.

4) H a ta, Y. 1967: Stereological studies on several ducts and vessels by injection method of acrylic resin. XVIII. On the buccal artery in some mammals. Okajimas Fol. anat. jap., 43, 331-361.

5) Kamijo, Y. 1967: Oral anatomy Vol. 3, Angiology. Tokyo, 421-521. (in Japanese)

6) K i t a m u a, H. 1970: Stereological studies on several ducts and vessels by in. jection method of acrylic resin. XXVI. Arterial distribution of the parotid gland in some mammals. Okajimas Fol. anat. jap., 47, 319-334.

7) Miller, M.E., G.C. Christensen and H.E. Evans 1964: Anatomy of the dog. Phila., 150-153, 289-312.

8) Taniguchi, Y., Y. Ohta and S. Tajiri 1952: New improved method for injection of acrylic resin. Okajimas Fol, anat. jap., 24, 259-267.

9) Taniguchi, Y., Y. Ohta, S. Ta jiri, H. Okano and H. Han a i 1955: Supplement to new improved method for injection of acrylic resin. Okajimas Fol. anat. jap., 27, 401-406.

10) Tsuji, O. 1969: Stereological studies on several ducts and vessels by injection method of acrylic resin. XXIII. Arterial distribution of the medial pterygoid muscle in some mammals. Okajimas Fol. anat. jap., 46, 21-40.

11) Tsusaki, T. 1954: Anatomy of the laboratory animals. Vol. 1, Rabbit, Tokyo, 184-187. (in Japanese)

12) Yoshikawa, T., T. Suzuki, R. Kiuchi and H. Matsuura 1961: The 
comparative anatomy of the Musculus masseter of the mammals. Acta anat. nippon., 36, 53-71. (in Japanese)

\title{
Explanation of Figures
}

\section{Key to Abbreviations}

\author{
M M. masseter \\ b Buccal artery \\ ce External carotid artery \\ f Facial artery \\ m Masseteric artery \\ ma Mandibular angle branch of the superficial temporal or \\ external carotid artery \\ s Submental artery \\ tda Anterior deep temporal artery \\ tdp Posterior deep temporal artery \\ tf Transverse facial artery \\ ts Superficial temporal artery \\ $\leftarrow \quad$ Direction of snout
}

\section{Plate I}

Figs. 1-8. Dog. .

Figs. 1-6. Lateral view.

Fig. 1. General aspect of the masseter. Rr. masset. (arrows) of the facial. C. $\times 0.8$. Figs. 2, 4. Middle $(\leftarrow)$ and distalmost Rr. masset. $(\rightarrow)$ of the facial. C. $\times 1.3$, C. $\times 1.0$. Fig. 3. R. masset. $(\swarrow)$ of the superficial temporal. C. $\times 2.0$.

Figs. 5, 6. Masseteric artery spreads supero-anteriorly to inferiorly $(\rightarrow, \downarrow, \leftarrow)$. R. masset. to the zygomaticomandibular muscle $(\uparrow)$. C. $\times 2.0$, C. $\times 1.8$.

Fig. 7. Inferior view. Proximalmost R. masset. $(\rightarrow)$ of the facial. C. $\times 2.0$.

Fig. 8. Superior view. The buccal artery runs lateralward. C. $\times 1.3$.

\section{Plate II}

Figs. 9-15. Rabbit.

Figs. 9, 10, 12, 15. Lateral view. C. $\times 2$, C. $\times 2$, C. $\times 2$, C. $\times 2.5$.

Figs. 11, 13. Inferior view.

R. masset. arising from the facial proximal to the vascular notch of the mandible $(\uparrow)$, at the notch $(\rightarrow)$, and proximal or distal to the labial arteries $(\downarrow)$. Venter of the maxillomandibular muscle $(\Delta)$. Supero-anterior $(x)$ and superior $(x \times)$ twigs of the transverse facial. C. $\times 2$.

Fig. 12. Arterial network of the intermediate masseter is shown by removal of that of the superficial masseter.

Fig. 14. Superior view.

R. masset. $(\rightarrow)$ of the buccal. Temporal muscular branches $(x)$. Maxillary alveoli $(\triangle)$. C. $\times 2.5$. 


\section{Plate III}

Figs. 16-21. Goat.

Figs. $16,17,19$. Lateral view. C. 1.0, C. $\times 1.5$, C. $\times 1.5$.

Figs. 18, 20, 21. Superior view.

R. masset. of the superficial temporal $(\downarrow)$. In case of figure 19, the welldeveloped proximalmost branch from the transverse facial runs downward as the mandibular angle branch. $R$. masset. of the deep temporal artery $(\leftarrow)$. Mandibular caput $(x)$. Rr. masset. of the buccal $(\uparrow)$ run superoposteriorly. C. $\times 2.0$, C. $\times 1.5$, C. $\times 2.0$.

\section{Plate IV}

Figs. 22-26. Human fetus.

Figs. $22,25,26$. Lateral view. C. $\times 1.5$, C. $\times 2.0$, C. $\times 2.3$.

Fig. 23. Inferolateral view. C. $\times 2.0$.

Fig. 24. Anterolateral view. C. $\times 2.3$.

Rr. masset. of the external carotid $(\uparrow)$, of the facial $(\leftarrow)$ and of the anterior deep temporal $(\rightarrow)$. R. masset. of the posterior deep temporal $(x)$. 
Arterial Distribution of Masseter Muscle in Some Mammals

Plate 1
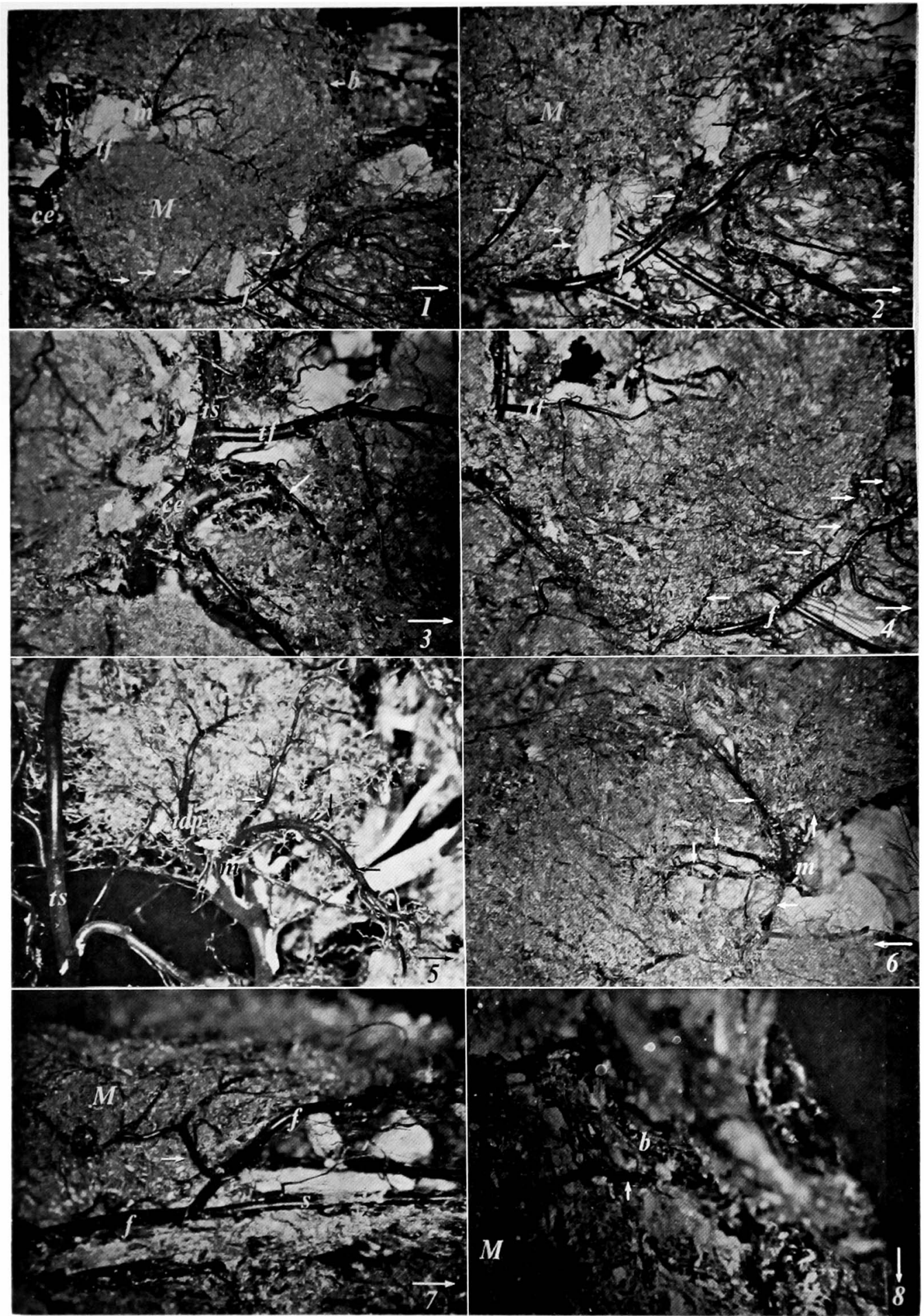

I. $F u j i w a r a$ 
350 .

Arterial Distribution of Masseter Muscle in Some Mammals

Plate II
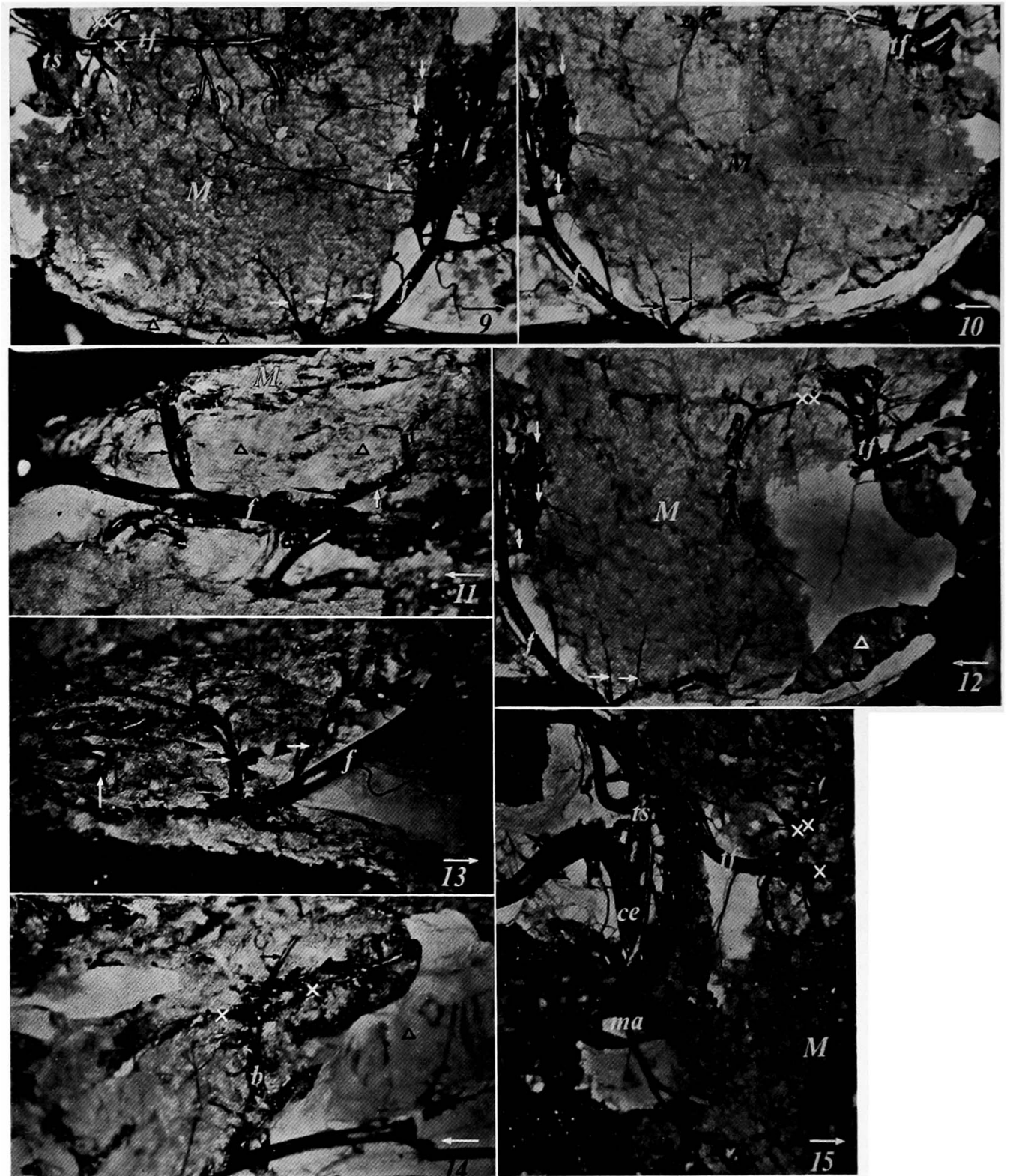

I. Fuji w a r a 
Arterial Distribution of Masseter Muscle in Some Mammals

Plate III
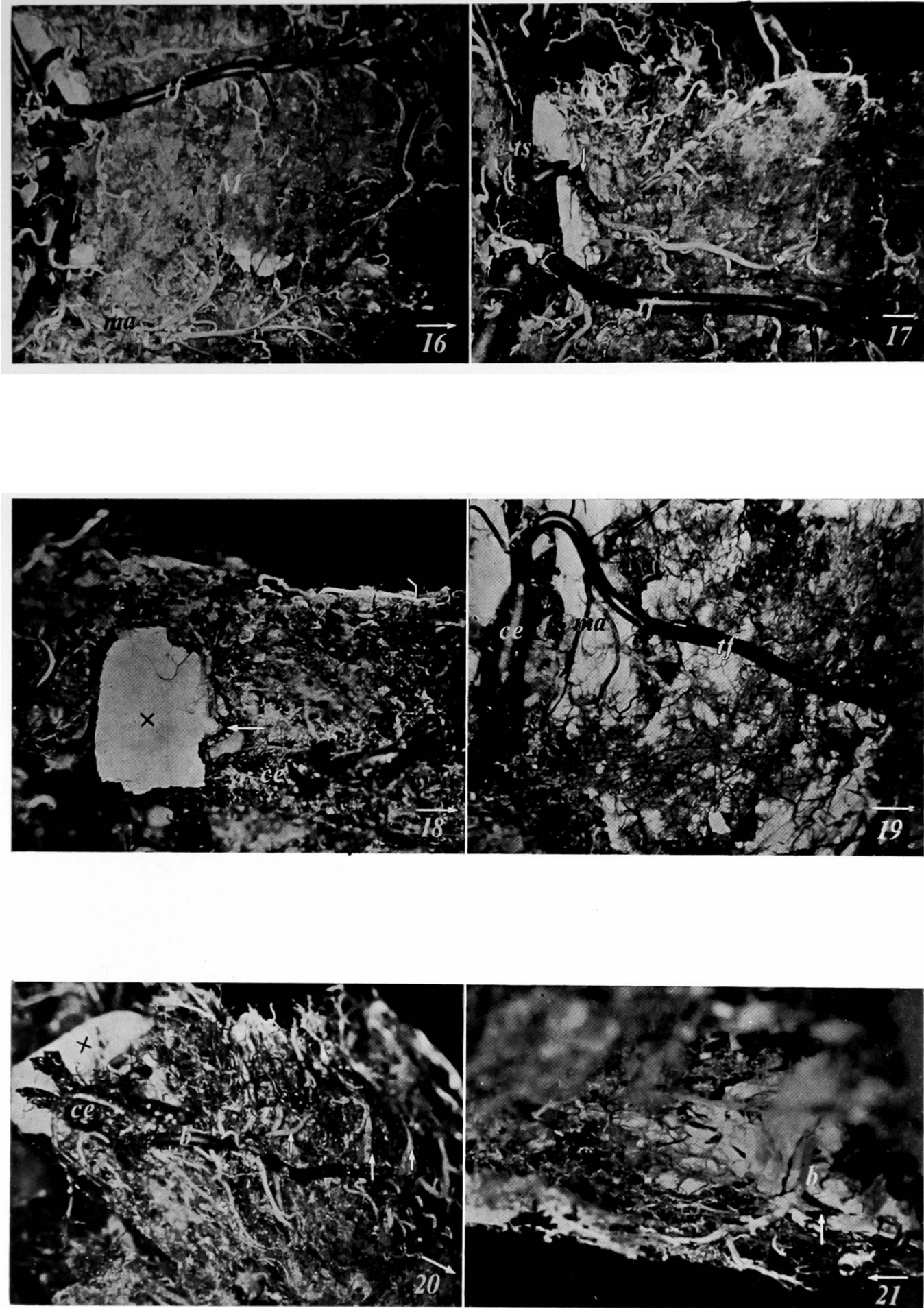

I. Fuji w a r a 
Arterial Distribution of Masseter Muscle in Some Mammals

Plate IV

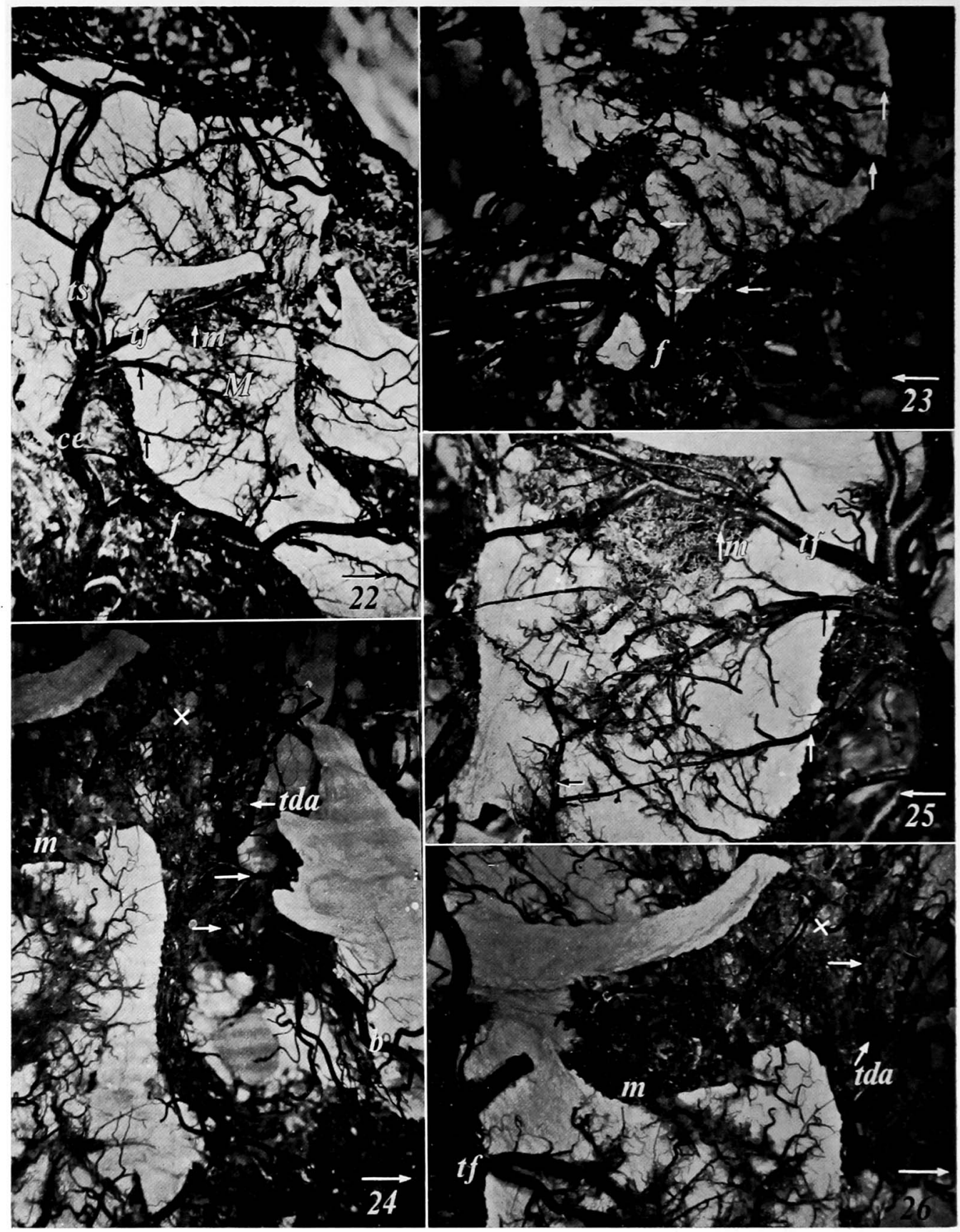

I. Fujiw a ra 